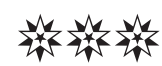

Artigos - Temas Livres

粼 



\title{
Políticas Territoriais de Segurança no BRASIL E NA FranÇa: UMA COMPARAÇÃo ENTRE as Unidades de Polícia Pacificadora - UPP e o Policiamento de Segurança do Cotidiano - PSQ
}

Wellington Clay Porcino

Polícia Federal - DF

$$
\approx
$$

\begin{abstract}
RESUMO
O presente trabalho tem como objetivo apresentar, de maneira breve, uma comparação entre a gestão do território no Brasil e na França, a partir dos reflexos nas Políticas Territoriais de Segurança implantadas em ambos os países, a partir do caso empírico das Unidades de Polícia Pacificadora - UPP e do Policiamento de Segurança do Cotidiano - PSQ na França. Para tanto, analisar-se-á os fatores que levaram a formação de áreas carentes denominadas favelas no Brasil, sua relação com a violência urbana, bem como as características comuns entre os problemas das áreas carentes no Brasil e na França e que permitem estabelecer paralelos entre as duas políticas acima citadas, seus problemas e qualidades.
\end{abstract}

Palavras-Chave: Gestão do território; Segurança pública; Políticas de segurança pública

\section{INTRODUÇÃ̃o}

No presente trabalho buscar-se-á analisar a Política de Unidades de Polícia Pacificadora, as UPP, última das diversas tentativas de minimizar os problemas de violência nas favelas e que apresentou, ao menos durante algum tempo, bons resultados, através da apresentação de seus problemas e acertos de tal programa, utilizando-se, para tanto, um paralelo com a Política de Segurança do Cotidiano (PSQ, em francês), vez que ambas tem como objetivo garantir a segurança da população mais exposta a violência em áreas carentes. 
Para tanto, serão utilizados achados da pesquisa de campo na França, realizadas durante estágio de doutorado realizado junto à Universidade de Paris III (Sorbonne-Nouvelle), tendo como fio condutor a gestão de segurança, uma vez que a existência de áreas em que o controle estatal do território é limitado constitui problema comum entre os dois países, embora haja uma grande diferença na sua intensidade e em seus reflexos para além dessas áreas.

Para tanto, apresentar-se-á a gênese e a dinâmica territorial das favelas cariocas que impactam diretamente a segurança pública, os resultados obtidos através das Unidades de Polícia Pacificadora, bem como uma comparação entre esta política pública e a PSQ francesa, para ao fim, apontar algumas medidas julgadas necessárias para o sucesso de programas como os aqui estudados.

Dessa feita, buscar-se-á, portanto, ao longo deste artigo, identificar, através da comparação entre duas políticas de segurança voltadas a comunidades carentes, quais ações poderiam ser implantadas a fim de obter-se melhores resultados nas UPP.

\section{Gestão do Território e as Favelas Cariocas}

No Brasil, o modelo de gestão do território mais utilizado é aquele herdado dos portugueses, o ordenamento do território, cujo principal objetivo é dispor de forma organizada os diversos usos do solo, como já discutido anteriormente. Diferencia-se da escola francesa, denominada Aménagement du Territoire, cuja principal meta é equalizar as diferenças regionais, através de um importante papel indutor exercido pelo Estado. Já a escola americana, o Spatial Planning tem como principal característica o relevante papel exercido pela inciativa privada na formulação da política de gestão do território (MONOD; CASTELBAJAC, 2010) (KRZYSZTOF, 2010).

Ao longo do presente tópico, discutir-se-á a origem das favelas da cidade do Rio de Janeiro, sua evolução, bem como de que forma a qualidade da gestão do território contribuiu ou não para a formação dessas comunidades.

Discutir-se-á, ainda, o Programa das Unidades de Polícia Pa- 
cificadora como projeto de gestão da segurança do território baseado no modelo de policiamento comunitário, à semelhança do programa de PSQ francês.

\subsection{As FAVElas no Rio de JANEIRo}

Inicialmente, cabe apresentar o conceito de favela a ser utilizado ao longo deste artigo. Cabe ainda esclarecer o uso do termo favela, ao invés do termo politicamente correto de "comunidade". Optou-se pelo primeiro, uma vez que se entende "comunidade" como um termo meramente eufemístico, e que, embora utilizado por residentes, foi construído por pessoas alheias a este espaço, e que por si só não tem o condão de afastar a carga de preconceito que reside no termo "favela".

Assim, em face de sua absoluta inutilidade em artigo científico, como o que se pretende, é que se decidiu não utilizar a palavra "comunidade" e sim favela no corpo do presente artigo, aliás, como ocorre na quase totalidade de publicações sobre o tema.

Contudo, cabe a pergunta: Qual o conceito de favela? Não há na literatura um consenso a respeito. A par da origem etimológica do termo, que se refere ao Morro da Favela, atualmente Morro da Providência, que era assim chamado pela abundância da planta assim denominada popularmente, e onde se deu a ocupação e criação da primeira favela carioca deve-se buscar identificar quais as características comuns das áreas assim denominadas.

Segundo Burgos (2004), favela seria tudo o que estivesse à margem da cidade, todo ou qualquer conjunto de habitações que estivesse fora do ideário de um certo local. Por exemplo, o ideário do bairro de Ipanema não comporta áreas pobres. Portanto, um aglomerado de habitações "pobres", independentemente de sua forma, isto é, prédio, morro, etc., é considerado uma favela.

Desse modo, entende-se como favela a área urbana de moradia destinada a pessoas de baixa renda, e com acesso limitado, em sua maioria das vezes, a serviços públicos como urbanização, iluminação pública, esgoto, água, luz, etc. 
É com esse sentido que o termo será empregado ao longo deste trabalho.

\subsection{A ORIGEM EA EVOLUÇão DAS FAVELAS NO RIO DE JA- NEIRO}

As favelas, como são chamadas as comunidades pobres com carência de infraestrutura urbana no Rio de Janeiro, tem sua origem no final do século XIX e início do século XX, dentro de um movimento de modernização da cidade, que levou à destruição dos cortiços, residências populares que se localizavam em sua região central, e que chegaram a abrigar cerca de $50 \%$ (cinquenta por cento) da população carioca entre os anos 1850-1870 (CAMPOS, 2004).

Contudo, com a proibição de construção de novos cortiços, bem como a já mencionada política de destruição dos já existentes, ocorreu um grande déficit habitacional para as famílias mais carentes, que não podiam se distanciar da região central da cidade, pois era exatamente ali que se localizavam os empregos (SILVA, 2010).

A gênese desse tipo de área, portanto, foi resultado da falta de moradias em quantidades suficientes para atender a camada populacional mais pobre que chegava à então capital do país no período entre o final do século XIX e início do século XX (ABREU, 1988).

Há, em consequência do movimento populacional acima mencionado, um crescimento significativo do déficit habitacional no Rio de Janeiro, o que contribui sobremaneira para um aumento da população residente nas áreas de favela. Assim, já a partir da década de 1930, elas se mostram relevantes tanto como preocupação política quanto como no tocante ao número de eleitores. Esse crescimento continua nas décadas seguintes e no censo de 1948, um total de $7 \%$ (sete por cento) dos habitantes da cidade, distribuídas ao longo das zonas Norte, Central e Sul já habitava nesse tipo de comunidade (VALLADARES, 1978).

O reduzido impacto das políticas de remoção, inicialmente entendidas como solução ao presente problema, deve-se, dentre outros fatores, à mencionada relevância eleitoral e medidas populistas e de 
assistencialismo destinadas às favelas, desde a década de 1950. Contudo, algumas remoções foram de fato realizadas, como por exemplo, a do Morro do Pasmado, em Botafogo, removida para a distante Vila Kennedy, próximo a Bangu, na Zona Oeste da cidade em 1964; e a do Parque Proletário da Gávea, cuja população foi removida para a Cidade de Deus, em 1970 (SILVA, 2010).

A partir da década de 1980, com o Governo Leonel Brizola e suas práticas clientelistas, dá-se início a uma nova forma de lidar com o problema das favelas. Isto se deu através de uma política de regularização fundiária, com o reconhecimento dos loteamentos irregulares e clandestinos, entendidos agora como solução para os problemas de moradia da população mais carente, legitimando-se, dessa feita, a ilegalidade (LAGO, 2003). Tal mudança na política acabou por levar a um abandono definitivo das políticas de remoção.

Os anos das décadas de 1990 e 2000 foram marcados por uma continuidade na política de urbanização das favelas, no sentido de prover infraestrutura básica a essas áreas. Programas como o Favela-Bairro são representativos dessa época. Tais políticas foram relativamente bem-sucedidas, promovendo uma substituição das casas de madeira e zinco por residências de alvenaria e permitindo que cerca de $98 \%$ (noventa e oito por cento) das residências em favelas possuam água e esgoto (SILVA, 2010).

Contudo, tais programas não puderam transpor o muro social que há entre a favela e os bairros ao seu redor. Somente a urbanização não tem o condão de garantir esta integração (CAVALLIERI, 2005).

Ao se analisar a figura 1, que apresenta um mapa com a distribuição das favelas na cidade do Rio de Janeiro, é necessário ressaltar que as áreas de favela nessa cidade possuem uma característica que as distingue das existentes em grande parte de outros municípios de grande porte. Enquanto em outras metrópoles, as comunidades carentes são encontradas em áreas afastadas de seus centros e de onde habitam as elites, no Rio de Janeiro, praticamente a metade (43\%) (CAVALLIERI, 2005) dessas áreas se encontram ou na região central ou na Zona Sul, região tradicionalmente ocupada pelas classes mais abastadas da sociedade carioca. 
Tal constatação implica na existência de uma tensão, uma complexa relação entre favela e "asfalto", como os moradores das próprias favelas costumam se referir aos bairros em seu entorno, favelas estas que estão em todas as regiões e zonas da cidade do Rio de Janeiro (CAVALLIERI, 2005).

A figura 1 apresenta um mapa elaborado com a distribuição das favelas na cidade do Rio de Janeiro.

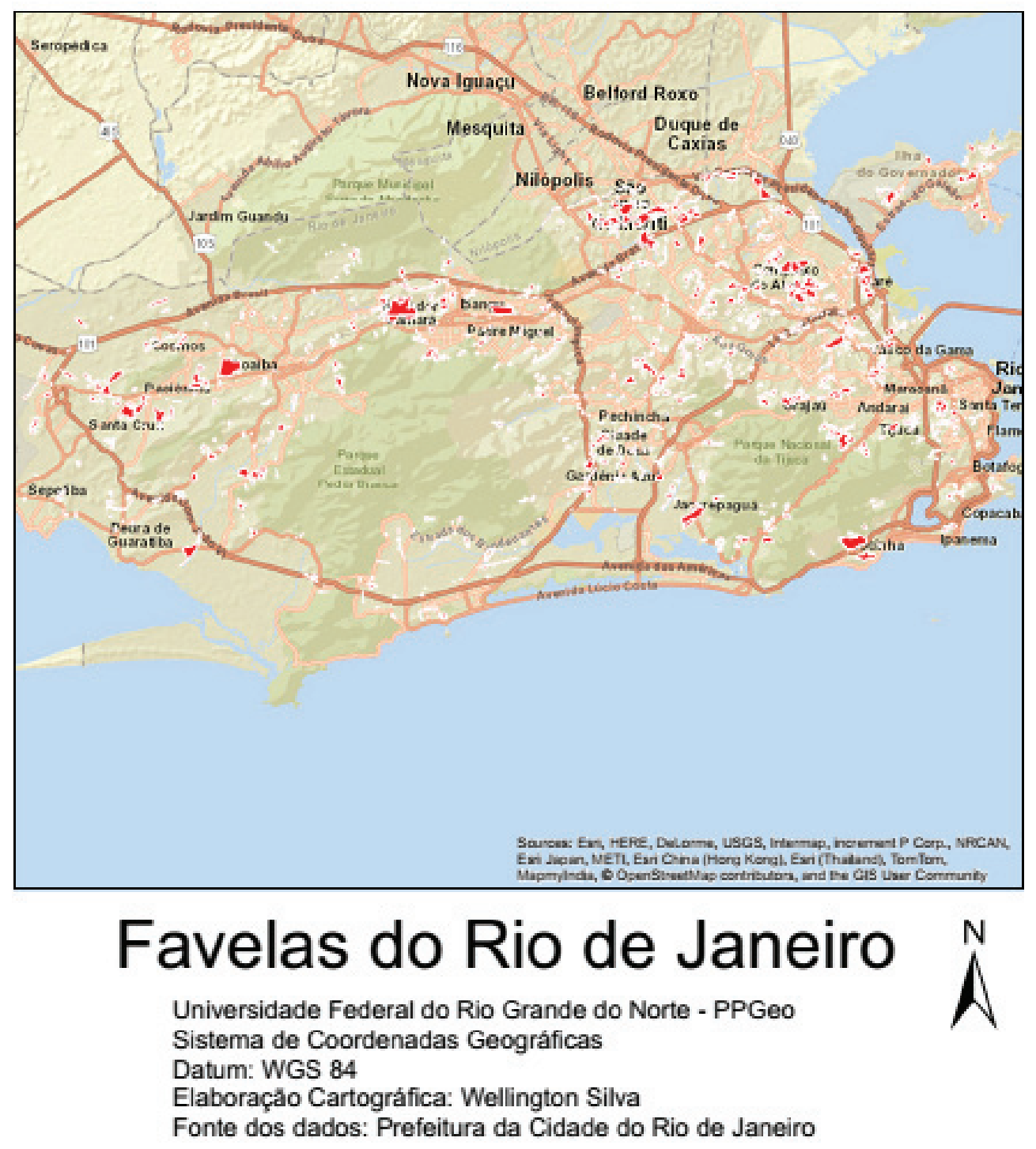

Figura 1 - Favelas da Cidade do Rio de Janeiro

\subsection{FAVELA E VIOLÊNCIA}

Até os anos de 1980, as favelas não eram conhecidas como si- 
nônimo de violência. No entanto, a partir daquela década, com o surgimento da facção criminosa denominada Comando Vermelho (CV), o tráfico de drogas começou a ocupar as regiões das favelas, aproveitando-se da ausência do poder público em muitas áreas. Até a década de 1990, esse domínio era absoluto, o que implicava em certa ausência de disputa por territórios. No entanto, a partir desse período, graças a diversas fragmentações e brigas internas outras facções foram criadas (ADA, TCP), dando início a uma disputa violenta pelo controle de pontos de vendas de drogas na cidade entre essas quadrilhas, que permanece até os dias de hoje (LESSING, 2008).

A violência de tais disputas era tanta que deu ensejo à introdução da principal diferença entre as disputas por pontos de venda de drogas no Rio de Janeiro e nas demais cidades do mundo, pois tais tipos de disputas ocorrem de maneira regular onde há tráfico de drogas (LESSING, 2008).

Contudo, no Rio de Janeiro, a violência de tais disputas atinge níveis inimagináveis em outras cidades, mesmo do Brasil, graças a utilização do fuzil, arma longa, de guerra e de grande capacidade, cujo uso é banalizado pelas facções criminosas cariocas, a ponto de serem utilizados mesmo em roubos de veículos particulares, etc.

Desse modo, no começo, como forma de defender seus pontos de venda de drogas das quadrilhas, e posteriormente da ação policial, o fuzil mudou toda a dinâmica territorial nas favelas.

O poder de fogo de tal armamento impôs às forças policiais dificuldade extra de atuação, o que praticamente excluiu as favelas das ações ordinárias de patrulhamento. Nesses lugares, a polícia só entrava com grande efetivo, em uma verdadeira operação de guerra, para depois se retirar imediatamente. Se a imagem das forças policiais junto às populações carentes não é boa de forma geral (GIBLIN, 2006), no Rio de Janeiro tal sentimento é amplificado, pois o policial não está presente no dia-a-dia, mostrando o lado positivo de seu trabalho, só entrando na favela em operações que se assemelham a uma guerra, com trocas de tiros intensas.

O domínio das quadrilhas de traficantes se intensificou, atuan- 
do em formas de rede e impactando não só as áreas das favelas e seu entorno, mas também todo estado do Rio de Janeiro (NOVELLINO; OLIVEIRA, 2019).Era necessário que uma alternativa se apresentasse. Assim, no ano de 2008, inicialmente na favela Dona Marta, localizada em Botafogo, Zona Sul da cidade, iniciou-se o programa das Unidades de Polícia Pacificadoras - UPP (RIBEIRO; VILAROUCA, 2018).

\subsection{AS UNIDADES DE POLÍCIA PACIFICADORAS}

Tal projeto tem como fundamento teórico o policiamento comunitário, modelo de gestão policial proposto no final dos anos 1960 nos Estados Unidos e que tem como principal objetivo recuperar a relação de proximidade entre a polícia e a comunidade por ela servida (RATCLIFFE, 2011).

A relação polícia-sociedade, em razão das transformações sociais e com as quais a polícia foi incapaz de lidar, foi se deteriorando com o passar dos anos. No Rio de Janeiro, tal situação foi ainda mais complexa pela forma de operação policial nas favelas, já descrita acima. No entanto, sendo a proximidade com a comunidade uma condição para o êxito do trabalho policial (BOBA, 2009), como resgatar a essa relação?

Foi, então, que em 2008, inicialmente no Morro Dona Marta, deu-se início à implantação das UPP. De lá, o projeto expandiu-se para 140 favelas de um total de 763, segundo o IBGE (MAGALONI, 2018).

Diferenciava-se de iniciativas semelhantes, tais como o Grupamento de Policiamento em Áreas Especiais - GPAE ou o ainda mais antigo Destacamento de Policiamento Ostensivo - DPO, pois além de efetivos capacitados em policiamento comunitário, o projeto incluía após uma primeira fase de ocupação, na qual era aplicada força policial máxima de modo que a polícia pudesse voltar a policiar áreas anteriormente sob o controle de facções criminosas - a manutenção de um efetivo considerável de policiais nas favelas, rompendo com a tática anterior de somente entrar nas áreas carentes durante a realização de operações.

Posteriormente, após a estabilização, o efetivo pode até mesmo ser reduzido, porém deve ser mantido um efetivo capaz de patrulhar 
efetivamente a região, empregando-se efetivos superiores ao utilizado em outras áreas não abrangidas pelo projeto. Assim, a implantação de tal tipo de política de gestão de segurança do território implica a utilização de um efetivo considerável.

No Rio de Janeiro, tal demanda foi atendida em parte com o aumento do efetivo da Polícia Militar, e outra parte por meio do pagamento do Regime Adicional de Serviço- RAS, espécie de hora extra paga aos policiais militares que trabalham durante as folgas.

A figura 2 apresenta um mapa com a distribuição das favelas onde foram implantadas UPP.

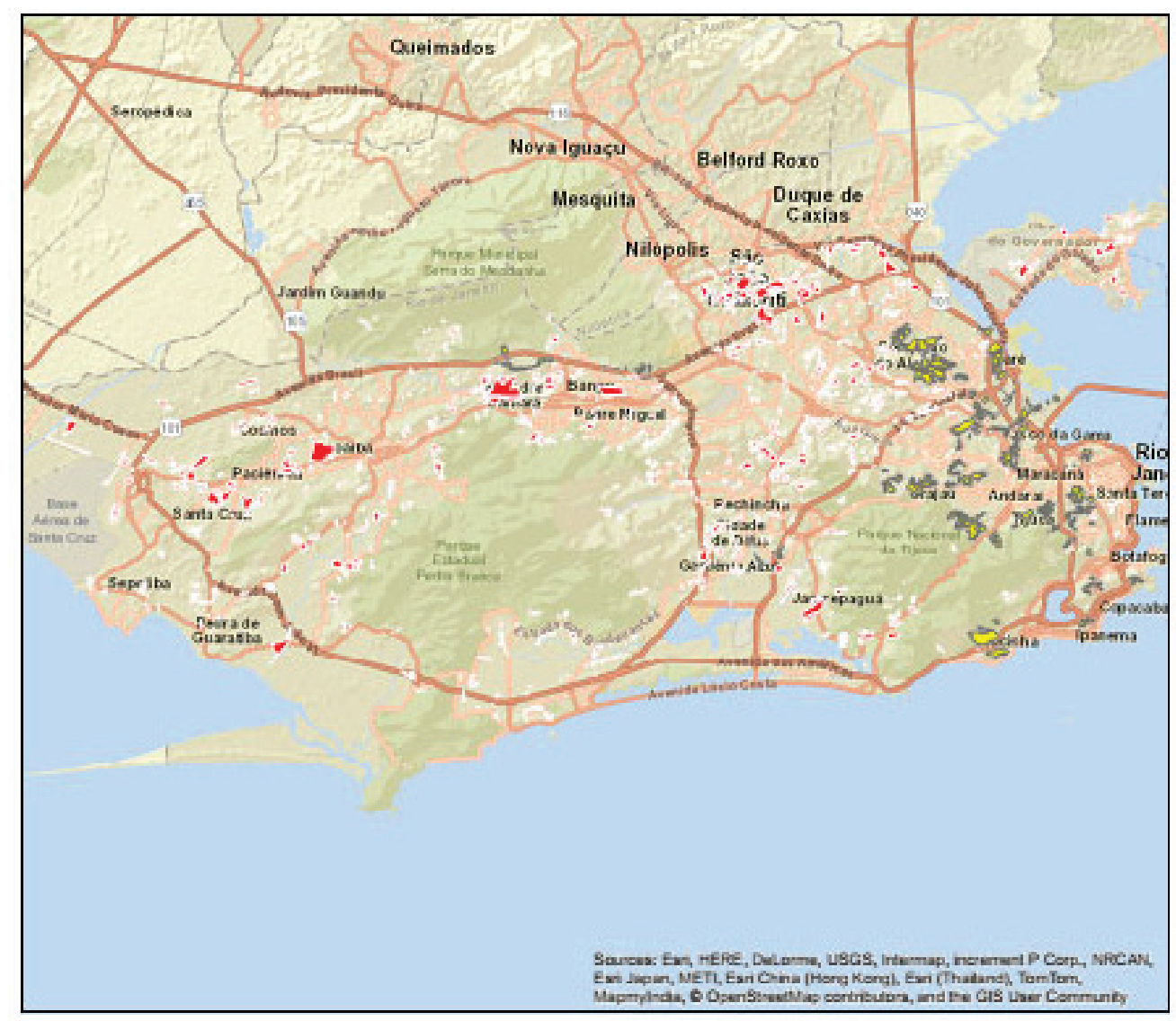

\section{Favelas com UPP}

Universidade Federal do Rio Grande do Norte - PPGeo

Sistema de Coordenadas Geográficas

Datum: WGS 84

Elaboraçăo Cartográfica: Wellington Silva

Fonte dos dados: Prefeitura da Cidade do Rio de Janeiro

Figura 2 - Favelas com UPP na cidade do Rio de Janeiro 
Da simples análise visual do mapa mencionado, verifica-se que há uma forte concentração de UPP nas Zonas Sul e Central da cidade, bem como próximo aos grandes eixos de tráfego do Rio de Janeiro (Avenida Brasil, Linhas Vermelha e Amarela). Tal fato gerou muitas críticas, uma vez que se acusou o estado de priorizar as áreas turísticas da cidade, em detrimento das áreas mais carentes e que mais sofriam com o controle dos criminosos sobre as favelas (LACERDA; BRULON, 2013).

No entanto, ocorreram alguns problemas na implantação do programa. O crescimento de efetivo da Polícia Militar não foi seguido de correspondente acréscimo na Polícia Civil. Desse modo, ao mesmo tempo em que as favelas eram ocupadas, não houve um trabalho de investigação adequado que poderia ter levado à identificação e à prisão das principais lideranças criminosas nas favelas, as quais permaneceram soltas, permitindo que reagrupassem forças e liderassem uma reação às UPP.

Ademais, o modelo de aumento de efetivo pelo pagamento da RAS não se mostrou sustentável, em grande parte devido à grave crise fiscal que se abateu sobre o estado do Rio de Janeiro, impedindo-o de pagar por esse reforço no policiamento.

Desse modo, já a partir do encerramento dos jogos olímpicos de 2016, pode-se perceber uma reação cada vez maior das facções criminosas em especial das grandes favelas do Rio de Janeiro, principalmente no Complexo do Alemão, que acabaram por impor ao policiamento pacificador uma atuação que lembrava muito mais as operações de antes do que o patrulhamento comunitário, com parte da capacitação e comando de UPP sendo assumidos por policiais com o perfil adequado a ações de combate e não de policiamento comunitário.

Além do mais, em todas as comunidades, o aumento de policiamento não foi seguido por outros serviços públicos e privados. $\mathrm{O}$ projeto UPP Social, que durante alguns meses buscou levar serviços públicos de qualidade às favelas com UPP, foi logo encerrado no estado e assumido pela prefeitura, e essa nunca investiu de forma adequada. Sem suporte político e a envergadura necessária nunca foi capaz de atender a enorme missão a que se propunha, deixando, portanto, a polícia como praticamente única presença do Estado nessas áreas. 
Desse modo, e diante da falta de outros agentes estatais, coube à polícia exercer papéis que não estão em suas atribuições originárias e para os quais não foi preparada. As UPP passaram a ser obrigadas a autorizar, dentre outras coisas, eventos culturais, como bailes, festas, etc. Ora, o exercício de tais funções regulatórias, para as quais não houve qualquer preparação do corpo policial, em comunidades que foram vítimas de completa anomia por décadas, acabou gerando conflitos e tornando a relação, já complexa entre polícia e sociedade, ainda mais complicada.

Em que pese a possibilidade legal de se atribuir partes da função regulatória à Polícia Militar, a utilização de seu efetivo para tanto tem se mostrado inadequada, apesar de alguns esforços de capacitação, os resultados obtidos apontam para uma inadequação dessa via, pois há dificuldades de comunicação entre polícia e comunidade e falta de atribuição da polícia para solucionar questões relativas a serviços públicos, como iluminação, saúde, dentre outros problemas (ROCHA, 2018).

Assim, diante do quadro acima descrito, não causa estranheza que o programa das UPP seja, neste momento, considerado um fracasso, após seu início auspicioso (RIBEIRO; VILAROUCA, 2018).

Contudo, como demonstra pesquisa realizada pela Universidade de Stanford, com apoio do Observatório de Favelas, em quatro favelas do Rio de Janeiro (Batan, Rocinha, Providência e Cidade de Deus) (MAGALONI, 2018) houve, de fato avanços em relação ao período que antecedeu a implantação do projeto.

Para chegar às conclusões aqui descritas foi aplicado um questionário com o objetivo de avaliar, dentre outros parâmetros, se os resultados obtidos pelas UPP foram ou não positivos para a comunidade. O questionário foi aplicado a 6.199 moradores das favelas acima mencionadas no período de dezembro de 2015 a março de 2016, utilizando como parâmetro de distribuição territorial os setores censitários, embora os entrevistadores também tenham sido orientados a buscar uma representatividade social (idade, cor da pele, gênero) na seleção da amostra.

Como resultado desse esforço, a pesquisa de Beatriz Magalo- 
ni (2018) permitiu perceber como as percepções a respeito das UPP variavam em razão da favela onde a pesquisa foi realizada. Por exemplo, a avaliação na favela do Batan é amplamente positiva, enquanto na Providência e na Cidade de Deus existe uma percepção neutra, identificando-se pontos negativos e positivos. Somente na Rocinha identificou-se uma percepção mais negativa em relação à UPP. Uma hipótese que pode explicar essa percepção é o impacto do crime de tortura seguida de morte com ocultação de cadáver de Amarildo Dias de Souza, delito cometido por policiais lotados na UPP da Rocinha, em 14 de julho de 2013.

Segue gráfico (figura 3) resumindo os resultados da pesquisa.

\section{VOCÊ ACREDITA QUE A INSTALAÇ̃̃O DA UPP NA [FAVELA] FOI POSITIVA PARA OS MORADORES?}

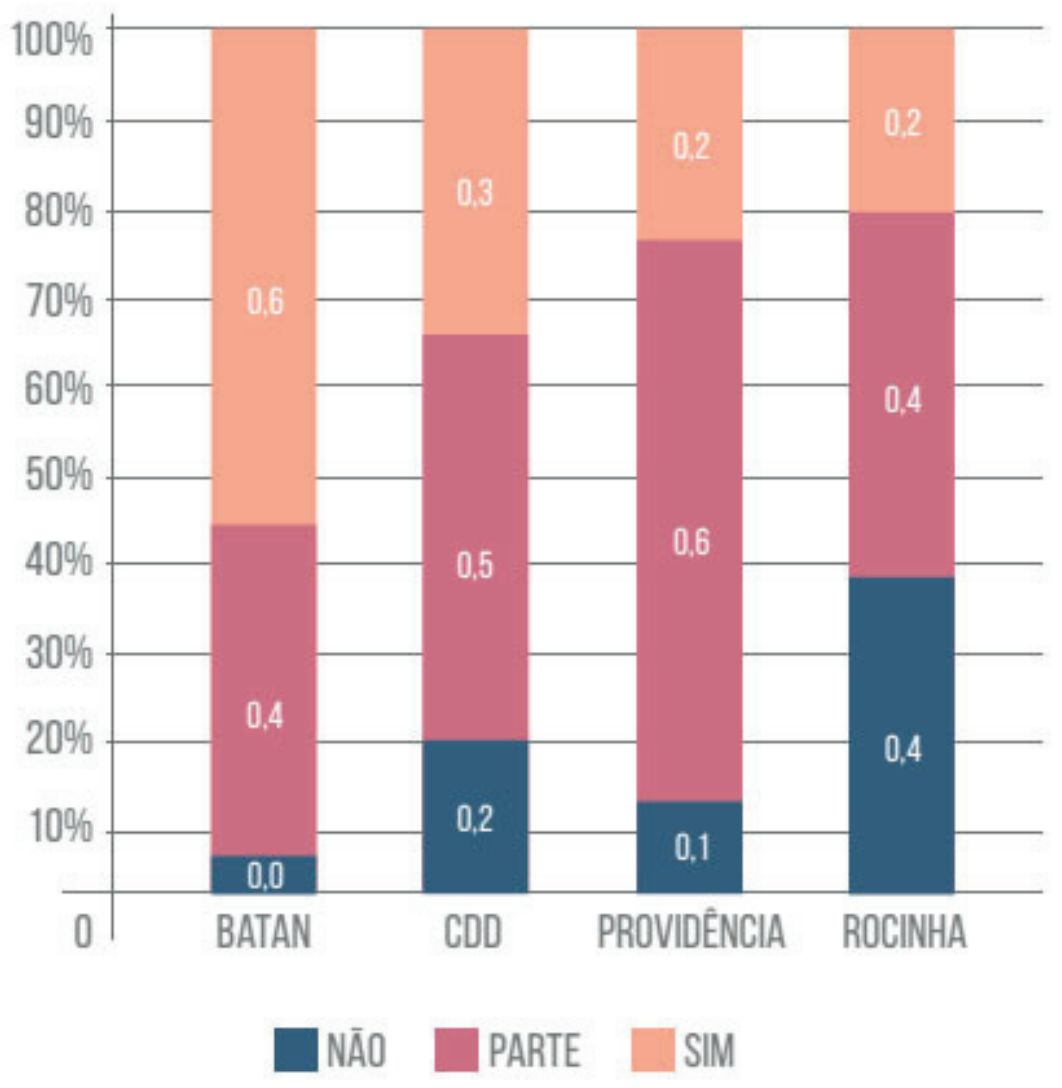

Figura 3 - Avaliação das UPP pelos moradores das favelas. Fonte: (MAGALONI, 2018)

Ainda, segundo a mesma pesquisa, os moradores hesitam em 
opinar pelo fim da UPP. Em que pesem todos os problemas apresentados, a maior parte dos moradores das favelas do Batan, da Cidade de Deus e da Providência não desejam o fim do programa. Apenas a Rocinha apresenta uma maioria relativa (30\%) de moradores favoráveis à saída da UPP. Porém, mesmo nessa localidade, $27 \%$ desejam a permanência, enquanto $43 \%$ não sabem opinar.

Desse modo, e a partir da pesquisa acima mencionada, não se pode afirmar que o projeto das UPP tenha sido um fracasso completo. Houve, sim, evoluções, embora pequenas em relação às expectativas iniciais. A pesquisa indica, inclusive, que os moradores do Batan consideram a UPP um sucesso.

Outro ponto que a pesquisa parece indicar é que a UPP funciona de maneira mais adequada em favelas pequenas, como o Batan, apresentando dificuldades graves de implantação nas favelas maiores.

Desse modo, se pode concluir dos dados acima, entre a avaliação da política pública das UPP como um fracasso absoluto ou um sucesso retumbante, há um programa com muitos erros e acertos, que apresenta graves problemas, porém com pontos positivos que podem ser reforçados. Afinal, não faz parte do ciclo de uma política pública sua avaliação, identificação de erros e acertos e correção de rumos?

\subsection{As favelas do Rio de Janeiro, o Programa das UPP E A GESTÃo do TERRITÓrio}

No Brasil, em razão da nossa herança ibérica, a corrente dominante de gestão do território é o chamado Ordenamento Territorial. Tal corrente se caracteriza, como já dito, por dedicar-se basicamente a distribuir no território zonas dedicadas aos diferentes usos, de modo a atingir determinados objetivos.

Políticas que se mostraram posteriormente equivocadas de gestão do território, como a destruição dos cortiços da área central do Rio de Janeiro para obras de revitalização, no início do século XX, sem que houvesse opção de moradia para o grande número de pobres desalojados, estão na origem do problema das favelas, como já mencionado. 
Também as políticas de remoção de comunidades e transferência para conjuntos habitacionais, distantes dos locais de origem da população em sua maioria, contribuíram em demasia para o crescimento do fenômeno em tela.

Como também se verificou na França, durante a pesquisa descrita no tópico a seguir, a arquitetura modernista agravou os problemas de segurança pública, com seus imensos conjuntos habitacionais, dificultando o acesso e a circulação das forças policiais. A grande aglomeração de pessoas em pequenos espaços e a carência de serviços públicos nesses locais acabaram por criar um senso de comunidade que os opunha aos moradores de fora dessa área, sentimento esse que pode levar à desumanização do outro (BACHMANN; LE GUENNEC, 2017).

O mesmo sentimento foi criado pela ausência total do Estado nas favelas que se desenvolveram fora dos conjuntos habitacionais no Rio de Janeiro. Como já dito, a ausência do Estado nessas áreas era praticamente absoluta. Essas favelas foram crescendo devido ao fenômeno do êxodo rural na segunda metade do Século XX, graças a ausência de políticas habitacionais, de ordenamento do território adequadas ao acolhimento desse expressivo contingente populacional (SILVA, 2010).

Assim, pode-se verificar que tanto políticas equivocadas de ordenamento territorial, bem como a ausência absoluta de políticas públicas de habitação contribuíram de forma significativa para o crescimento das favelas no Rio de Janeiro.

Mesmo ações que se preocuparam apenas com o ordenamento territorial e a urbanização, como o "Programa Favela Bairro", que organizou e urbanizou a quase totalidade das favelas cariocas durante a década de 1990, tendo, portanto, êxito no que se propôs, obteve resultados pífios no tocante ao desenvolvimento social e à segurança pública nas áreas contempladas (CAVALLIERI, 2005).

Não houve incentivos ao empreendedorismo, não se inovou na educação, enfim, foi um projeto que buscou meramente ordenar o território, entendido como tão somente os fixos que o compõe (CAVALLIERI, 2005). A mesma crítica pode ser feita ao programa das UPP. As polícias foram deixadas como responsáveis pela segurança 
pública e pela regulação do território, função essa que deveria ser exercida pelo município e para a qual a polícia não é e nem deve ser preparada (MAGALONI, 2018).

Ademais, investimentos sociais não foram realizados, nem mesmo houve incentivos à implantação de empreendimentos privados na região. Desse modo, não há como se esperar sucesso, pois a segurança pública é muito mais que a função policial. É necessário um Estado presente e capaz de atender às necessidades básicas da comunidade, bem como de apresentar mecanismos de saída de situações de pobreza. E nisso, de fato, as UPP falharam, pois não houve, por parte dos demais atores estatais o apoio necessário ao seu sucesso (RIBEIRO; VILAROUCA, 2018).

E, nos locais onde tal política ainda poderia ser reconhecida como um sucesso, como na Favela do Batan, isso se deve muito mais a fatores locais, tais como pouca força do grupo criminoso que anteriormente ocupava a área, pequena extensão territorial que facilita a atuação policial, etc., do que às políticas públicas implantadas (MAGALONI, 2018).

\section{Políticas Públicas Territoriais de Gestão da Seguranç na França}

Ao longo deste tópico, apresentar-se-ão os resultados das pesquisas de campo realizadas na França a respeito da gestão de segurança do território, com especial ênfase nos achados referentes ao tratamento de tal questão nas áreas carentes ao redor de Paris, as cités.

Para a realização de tal trabalho, além de pesquisa bibliográfica, foram realizadas entrevistas com policiais franceses, tanto da Polícia Nacional quanto da Gendarmerie, não só nas sedes das unidades, mas também com visitas ao terreno, à sede da Polícia Nacional no Departamento de Seine-et-Marne, bem como nos comissariados a ela subordinados e, de especial relevância, uma visita à Noisiel, onde foi possível conhecer uma cité e interagir com seus moradores, entrevistando-os, ainda que de forma não estruturada. 
Optou-se por realizar o presente estudo na França pois foram identificados problemas semelhantes nas grandes cidades brasileiras e francesas no campo da segurança pública, em especial no tocante ao exercício do poder estatal legítimo sobre determinadas áreas carentes. Ademais, as soluções buscadas para a questão são semelhantes, isto é, a adoção de políticas territoriais de segurança, a saber, o Policiamento de Segurança do Cotidiano na França (PSQ, da sigla em francês) e, no Rio de Janeiro, as Unidades de Polícia Pacificadoras - UPP.

O PSQ é um programa recente, tendo sido implantado no local da pesquisa somente em janeiro de 2018. Ao contrário das UPP que é uma política que conta já com dez (10) anos de implantação.

Cabe, neste ponto, uma breve descrição do contexto no qual se desenvolve o programa de PSQ. Tal programa é, na verdade, o reflexo na segurança pública do programa de gestão do território do governo francês denominado Quartiers Prioritaire de la Politique de la Ville - QPPV, cuja implantação, a partir de 2014, deu-se em substituição a dois programas anteriores, as Zonas Urbanas Sensíveis - ZUS e os Contratos Urbanos de Coesão Social.

Enquanto as ZUS tinham como objetivo fomentar o desenvolvimento econômico, através de concessão de vantagens fiscais ou concorrenciais a empresas que se instalassem nessas áreas, pelo atendimento de alguns requisitos legais; os Contratos Urbanos de Coesão Social representavam uma ação política contratual, que gerava créditos para aqueles que aderissem aos ditos "contratos", onde os benefícios e as obrigações de entidades privadas e órgãos públicos eram previstos.

Tais políticas foram, em busca de maior eficiência, reunidas numa única, os Quartiers Prioritaire de la Politique de la Ville - QPPV, cujos objetivos previstos em lei seriam o estímulo à coesão urbana e a difusão de um sentimento de solidariedade nacional e mesmo local em relação aos locais identificados como os mais críticos, a partir do critério de renda média em comparação com o mesmo valor médio nacional e de seu entorno.

Tal política tem como principal diferencial a importância do papel exercido pela comunidade, representada pelos moradores, em- 
presários e associações representativas das áreas em tela, na seleção das ações a serem realizadas prioritariamente, através do contract de ville, documento no qual são estabelecidas de forma clara as obrigações e responsabilidades de cada uma das partes envolvidas, poder público e sociedade civil. Mantém-se, também, a política de concessão de incentivos fiscais para investimentos de natureza comercial, mobiliária ou industrial nas regiões abrangidas pelos QPPV.

Foram apontados em 2015, em toda a França metropolitana, 200 (duzentos) QPPV, distribuídos conforme a figura 4.

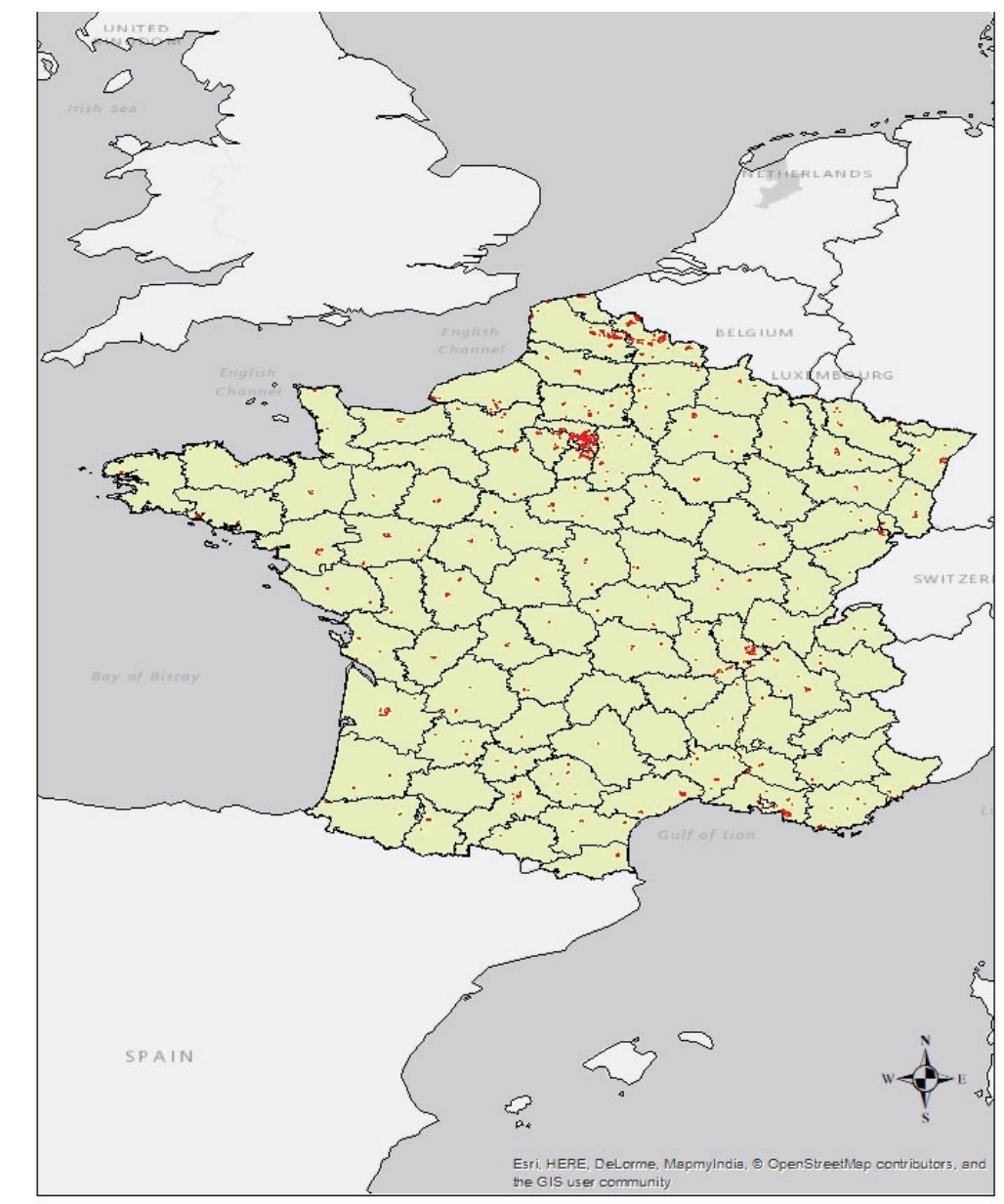

Quartiers Proritaires de la Politique de la Ville

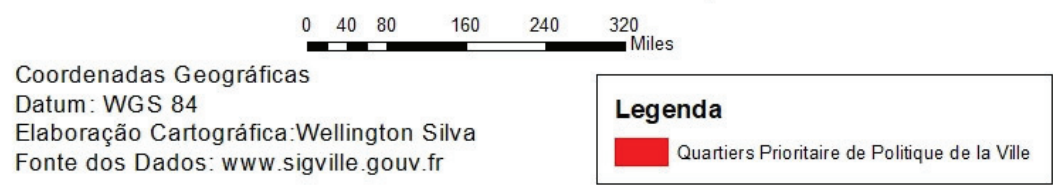

Figura 4 - Distribuição dos Quartiers Prioritaire de la Politique de la Ville

O Policiamento de Segurança do Cotidiano - PSQ é o reflexo, na política de segurança pública, das políticas adotadas a partir dos 
QPPV.

Contudo, o PSQ não é a primeira experiência francesa com policiamento de proximidade. Já faz 20 (vinte) anos que a polícia francesa vem tentando implantar tal modelo de policiamento em suas áreas mais críticas, conhecidas como cités.

Contudo, durante todo esse tempo os resultados não foram, na maior parte dos lugares, adequados. Uma avaliação dos problemas que levaram ao fracasso dos projetos anteriores de polícia de proximidade apontou para uma causa principal: a falta de participação de outros atores estatais e privados na elaboração e implantação do projeto de segurança para as comunidades.

É justamente essa lacuna que o PSQ busca suplantar, pois como foi apontado na pesquisa de campo, sua principal característica é que a polícia não é mais o único ator envolvido, embora se mantenha relevante. O PSQ envolve várias outras instituições e se enquadra em um programa de gestão do território mais amplo, como já dito, o Quartiers Prioritaire de la Politique de la Ville, no qual há previsão de fortes investimentos em educação e em geração de renda nas comunidades carentes.

\section{Comparação entre as Políticas públicas Territoriais de Gestão da Segurança na FranÇA E NO BRASIL}

Ao analisar o programa das UPP em comparação às experiências francesas, identifica-se a mesma lacuna encontrada nos programas anteriores ao PSQ daquele país: a polícia como presença praticamente única do Estado. Somente a polícia tem participação ativa nas UPP, enquanto que para que esse projeto fosse, de fato, bem-sucedido seria necessário que outros atores estatais e privados o integrassem (LACERDA; BRULON, 2013) (MAGALONI, 2018) (RIBEIRO; VILAROUCA, 2018).

Outro achado de pesquisa relevante que surgiu durante as entrevistas e visitas realizadas na França e que não foi observado no 
Brasil, refere-se a uma etapa anterior à ocupação pela polícia dos espaços públicos, caracterizada por um trabalho exaustivo de investigação e inteligência, de modo a enfraquecer o grupo criminoso que controlava a área em questão.

Tal ação foi apontada como fundamental nas entrevistas realizadas junto a policiais franceses como forma de garantir sustentabilidade e reduzir resistências às etapas seguintes à implantação do PSQ. Não só inteligência, mas de fato investigação criminal, de modo que se possível a prisão antecipada de líderes de facções criminosas locais possa reduzir as resistências à fase inicial de implantação.

Por óbvio, as dificuldades encontradas no Brasil são maiores, pois a organização e a ostensividade do controle territorial acarretam uma maior agressividade dos criminosos em relação à polícia (NOVELLINO; OLIVEIRA, 2019), o que leva a confrontos violentos entre essas quadrilhas e as forças policiais.

Tais dificuldades se apresentam principalmente no momento da entrada da polícia, com maiores consequências se não houver um trabalho de investigação adequado e podem ser enfrentadas, como aliás a própria política das UPP já demonstrou.

Um complicador que existe na França e não no Brasil é a questão da origem da comunidade, muitas vezes composta por descendentes de imigrantes, o que dificulta a a integração das cité ao seu entorno. No Brasil, essa questão não se apresenta como relevante. Contudo, a diferença social entre a favela e o seu entorno podem ter impactos ainda maiores do que os encontrados na França em relação às dificuldades de integração.

Da experiência francesa, ainda, podemos destacar que, como ocorreu em Melun e Chessy, cidades localizadas também no Departamento de Seine-et-Marne e que se caracterizam por reduções significativas em seus índices de criminalidade, a execução de políticas de gestão do território adequadas, mesmo onde essas políticas tenham um forte componente privado, como em Chessy, graças ao impacto do complexo da Euro Disney que ali se localiza, podem ter impactos positivos no tocante à segurança pública. 
Como forma de destacar o resultado do comparativo realizado entre as políticas de UPP e PSQ, apresenta-se a tabela 1.

\begin{tabular}{c|c} 
UPP (Brasil) & PSQ (França) \\
\hline $\begin{array}{c}\text { Polícia como representação única do } \\
\text { Estado nas áreas onde a política foi } \\
\text { implantada. }\end{array}$ & $\begin{array}{c}\text { Polícia tem participação relevante mas } \\
\text { não é o único ator estatal envolvido. }\end{array}$ \\
\hline $\begin{array}{c}\text { Foco principal nas ações ostensivas no } \\
\text { momento da ocupação. }\end{array}$ & $\begin{array}{c}\text { Trabalho exaustivo de investigação } \\
\text { e Inteligência, incluindo prisões das } \\
\text { principais lideranças criminosas locais, } \\
\text { a fim de minimizar a resistência para a } \\
\text { implantação da política. }\end{array}$ \\
\hline $\begin{array}{c}\text { Questões étnicas não são relevantes. } \\
\text { ça social entre a favela e seu entorno. }\end{array}$ & $\begin{array}{c}\text { Problema criado por questões étnicas e } \\
\text { de imigração impactam sobremaneira o } \\
\text { programa. }\end{array}$ \\
\hline $\begin{array}{c}\text { Inexistência de Programas de Geração } \\
\text { de Renda e de Incentivos Fiscais para } \\
\text { investimentos nas áreas contempladas } \\
\text { na política. }\end{array}$ & $\begin{array}{c}\text { Programas de Geração de Renda e de } \\
\text { Incentivos Fiscais para investimentos } \\
\text { como pontos relevantes da política. }\end{array}$ \\
\hline
\end{tabular}

Tabela 1. Comparação entre PSQ e UPP

\section{Conclusão}

Ao longo do presente trabalho buscou-se analisar políticas de gestão de segurança do território na França e no Brasil, tendo como pano de fundo políticas de segurança pública denominadas policiamento de proximidade e adotadas em ambos os países.

A partir de dados obtidos em pesquisa de campo, foi possível traçar um panorama dos programas de gestão de segurança voltados às áreas mais carentes, as cités, e do modelo de gestão do território na França, bem como estabelecer seus resultados, erros e acertos.

Em relação ao Rio de Janeiro, a partir de revisão bibliográfica e pesquisa junto à Secretaria de Segurança Pública, buscou-se traçar um paralelo, em relação às políticas de segurança nas favelas. Objetivou-se apontar alguns erros em políticas de gestão do território que levaram ao surgimento e expansão das favelas, bem como seus impactos em relação à segurança pública.

Analisou-se, a partir do ponto de vista territorial, a política das Unidades de Polícia Pacificadora, alguns de seus resultados, acertos e erros. 
Ao comparar-se as políticas de segurança na França e no Rio de Janeiro, verificou-se que os problemas apresentados na implantação dessas ações possuíam similaridade. Atribuiu-se às polícias um papel muito além de suas funções e capacidades, limitando-se a entender a segurança pública como um mero problema de repressão. Assim, onde o Estado só se fez presente com a polícia, não buscando atender as demais demandas sociais da população, o programa fracassou, a tal ponto que, na França, iniciou-se novo projeto, o Policiamento de Segurança do Cotidiano - PSQ, no qual o papel de outros atores estatais vêm se somar aos esforços da polícia.

Enfim, após o aqui explanado, pode-se afirmar, sem qualquer dúvida, que há uma ligação estreita entre gestão do território e política de segurança pública. Não há como se fazer segurança sem uma adequada gestão do território, mas também deve se ter em mente as consequências que a má gestão do território impõem à segurança pública.

Dessa feita, para que as políticas territoriais de segurança atinjam resultados adequados, é necessário que se veja o território não como algo a se ordenar somente, é necessário encará-lo como território usado, sinônimo de espaço geográfico, como híbrido indissociável dos sistemas de objetos e de ações (SANTOS, 2006). Assim, a polícia não seria mais o único ator envolvido no programa das UPP. Seria um parceiro relevante, mas somente um dentre vários, como busca implantar o PSQ.

Tal constatação aparece muito clara nas entrevistas com autoridades policiais francesas. Pode-se, de fato, afirmar que não existe política de segurança pública executada só pela polícia com bons resultados, bem como que o território e sua gestão são fatores relevantes a serem considerados quando da formulação de políticas de segurança pública.

Wellington Clay Porcino

Polícia Federal

Delegado de Polícia Federal. Doutor em Geografia PELA UFRN, COM ESTÁGIO DE DOUTORAdo na Universidade Paris III ( Sorbonne Nouvelle). Mestre em Sistemas de Informações Geográficas pela Universidade Nova de Lisboa. Mestre em Operações Militares pela EsAO/EB. Especialista em CiênCia Policial e Inteligência pela ANP. Especialista em Atualização Pedagógica pela UfRJ. Especialista em Direito Penal e Processual Penal pela Universidade 
Gama Filho. Foi Chefe do SIP/SR/DPF/RJ, da Divisão de Doutrina de Inteligência Policial da DiP e dA

Divisão de Repressão aOs CRimes Ambientais da DICOR E SR/PF/RR E SR/PF/RN E DiRETOR DA SENASP/

MJSP. ATUALMENTE EXERCE A FUnÇÃo de COORdenador de Gestão Estratégica da Polícia Federal

\title{
Territorial Security Policies in Brazil AND FRANCE: A COMPARISON BETWEEN the Pacifying Police Units - UPP and Everyday Security Policing - PSQ
}

\begin{abstract}
This paper aims to present, in a brief way, a comparison between the management of the territory in Brazil and in France, based on the reflexes in the Territorial Security Policies implemented in both countries, based on the empirical case of the Units of Pacifying Police (UPP) and Daily Security Policing (PSQ) in France. In order to do so, we will analyze the factors that led to the formation of poor areas called favelas in Brazil, their relationship with urban violence, as well as the common characteristics among the problems of poor areas in Brazil and France, between the two policies mentioned above, their problems and qualities.
\end{abstract}

KEY Words: Territorial management; Public security; Public security policies

\section{Politiques de Sécurité Territoriale au Brésil et en France: Une Comparaison entre les Unités de Police Pacificatrices la Police de Sécurité Quotidienne - PsQ}

\section{RÉSUMÉ}

Cet article a pour objectif de présenter, de manière succincte, une comparaison entre la gestion du territoire au Brésil et en France, basée sur les réflexes des politiques de sécurité territoriale mises en ouvre dans les deux pays, à partir du cas empirique des Unités de Police de pacification (UPP) et police de sécurité quotidienne (PSQ) en France. Pour 
ce faire, nous analyserons les facteurs qui ont conduit à la formation de zones pauvres appelées favelas au Brésil, leur relation avec la violence urbaine, ainsi que les caractéristiques communes des problèmes des zones pauvres au Brésil et en France, entre les deux pays. politiques mentionnées ci-dessus, leurs problèmes et leurs qualités.

Mots Clés: Gestion territoriale; Sécurité publique; Politiques de sécurité publique

\section{REFERÊNCIAS BIBLIOGRÁfICAS}

ABREU, M. Evolução Urbana do Rio de janeiro. IPLANRIO. Rio de Janeiro: Ed. Jorge Zahar, 1988.

BACHMANN, C. ; LE GUENNEC, N. Violences Urbaines: ascension e chute des classes moyennes à travers de cinquante ans de la politique de la ville. Paris: Albin Michel, 2017.

BOBA, R. Crime Analysis with Crime Mapping. Beverly Hills: Sage Publications, 2009.

BRASIL. Ministério da Integração Nacional. Subsídios para a Definição da Politica Nacional de Ordenamento Territorial - PNOT (Versão Preliminar). Brasília: [s.n], 2006.BURGOS, M. B. Dos Parques Proletários ao favela-bairro: As políticas públicas nas favelas do Rio de Janeiro. Em: A. A. M. ZALUAR, ed. Um século de Favela. Rio de Janeiro: Ed. FGV, p. 25-60, 2004.

CAMPOS, A. Do Quilombo a favela. A produção do espaço "criminalizado" no Rio de Janeiro. Rio de Janeiro: Ed. Bertrand Brasil, 2004.CAVALLIERI, F. O Momento 2000 do programa FavelaBairro: avaliação com base nos censos 1991 e 2000. Rio de Janeiro: Coleção Estudos Cariocas/IPP, 2005.

GIBLIN, B. Ghettos américains, banlieues françaises. Hérodote, Volume 122, p. 3-9, 2006.

KRZYSZTOF, G., KRISTOF, V. A. \& JÓZEF, H. Spatial planning in the Uited States of America and Poland. Infrastructure and ecology of rural areas, Volume 11, p. 53-69, 2010.

LACERDA, D. \& BRULON, V. Política das UPPs e espaços organizacionais precários: uma análise de discurso. Revista da Administração de Empresas, 53(2), 2013. 
LAGO, L. C. d. Favela-loteamento: reconceituando os termos da ilegalidade e da segregação urbana. Cadernos Metrópole, n. 9 (1 Sem.), p. 119-133, 2003.

LESSING, B. As Facções Cariocas em Perspectiva Comparativa. Novos estudos - CEBRAP, Volume 80, p. 43-62, 2008.MAGALONI, B. Percepção de Moradores sobre Segurança Pública e os Dilemas de Polícia Pacificadoras em Favelas do Rio de Janeiro. Rio de Janeiro: Laboratório de Pobreza, Violência e Governança da Universidade de Stanford, 2018.

MONOD, J. ; CASTELBAJAC, P. L'Aménagement du Territoire. 15a ed. Paris: Presses Universitaires de France, 2010.NOVELLINO, M. S. ; OLIVEIRA, L. A. V. Territórios-Rede do Crime Organizado no Rio de Janeiro. Natal, Anais XVIII ENANPUR 2019.

RATCLIFFE, J. H. Intelligence Led-Policing. New York: RoutdledgeRIBEIRO, L. ; VILAROUCA, M. G. "Ruim com ela, pior sem ela": o desejo de continuidade das UPPs para além das Olimpíadas. Revista de Administração Pública, 52(6) ROCHA, L. M., CARVALHO, M. B. ; DAVIES, F. A. Crítica e controle social nas margens da cidade: etnografia de espaços de participação em favelas "pacificadas" do Rio de Janeiro. Revista de Antropologia da UFSCar, 10(1), p. 216-237SANTOS, M. A Natureza do Espaço: técnica e tempo. Razão e emoção. São Paulo: EdUSPSILVA, M. d. N. A Favela como expressão de conflitos no espaço urbano do Rio de Janeiro: o exemplo da Zona Sul carioca. Dissertação apresentada como requisito parcial para a obtenção do título de Mestre em geografia pela PUCRIO. Rio de Janeiro: [s.n.]

VALLADARES, L. Passa-se uma casa: Análise do programa de remoção de Favelas do Rio de Janeiro. Rio de Janeiro: Zahar editores

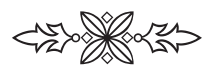

